\title{
Requirement of the assessment strategy for biosphere in mature safety cases for nuclear waste repositories - Finland case
}

\author{
A. T. K. IKONEN ${ }^{*}$
}

Environmental Research and Assessment EnviroCase, Ltd., Hallituskatu 1 D 4, 28100 Pori, Finland

[Received 10 October 2014; Accepted 9 July 2015; Associate Editor: Nick D. Bryan]

\section{ABSTRACT}

In safety assessments for nuclear waste disposal, the biosphere is a completely open system, whereas the bedrock can be treated with comparably simple boundary conditions. The bedrock has a vital role in providing and maintaining favourable conditions for the waste, but the public interest tends to focus on the biosphere. More importantly, the bedrock groundwater does arrive from the biosphere. Also, the regulations usually set the safety criteria in terms of doses occurring in the biosphere. Thus, it is reasonable to address the biosphere as a part of the disposal system, performance of which should be described based on conceptual models that cover phenomena and processes controlling radionuclide release and transport. From these, the actual assessment models and data are expected to be derived based on high-level research and expertise obtained through empirical study. In this paper, the complexity expected of a biosphere assessment within a mature safety case is discussed through the example of the Finnish regulations and recent safety cases for nuclear waste disposal. Both elaborate and complex presentations and stylised approaches have their benefits, and a balance needs to be sought.

Kerwords: safety case, safety assessment, nuclear waste disposal, requirements, complexity, confidence.

\section{Introduction}

IN deep geological disposal for nuclear waste, the biosphere is generally treated separately from the geosphere and the engineered barrier system. Whereas the geosphere is comparably eternal and unchanging, and thus relatively easy to model as a semi-closed system with relatively simple boundary conditions, the biosphere is a completely open system in continuous change. The bedrock, or other host formation, has a vital role in providing and maintaining favourable conditions for the waste
* E-mail: ari.ikonen@envirocase.fi

DOI: $10.1180 /$ minmag.2015.079.6.36 packages, but the public interest tends to focus on the biosphere. Also more importantly, the deep groundwater does arrive from the biosphere. In addition, the safety criteria are set in most regulations in terms of radiation doses or radiological risks that do occur in the biosphere.

Based on this, the recently revised guide (STUK, 2014) of the Finnish nuclear safety authority considers the biosphere as a part of the disposal system, performance of which is required to be described based on conceptual models that cover phenomena and processes controlling radionuclide release and transport. From these, the models and data used for the actual assessment calculations are to be derived, usually through simplification, based on high-level research and expertise obtained through
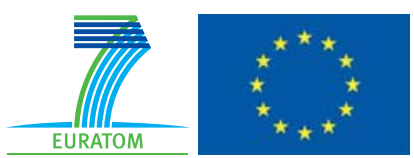

The publication of this research has been funded by the European Union's European Atomic Energy Community's (Euratom) Seventh Framework programme FP7 (2007-2013) under grant agreements $n^{\circ} 249396$, SecIGD, and $n^{\circ} 323260$, SeclGD2. 
empirical study (e.g. site characterization, laboratory experiments and research on natural analogues).

Furthermore, expectations of the public exhibit much emphasis on comprehensive treatise of the biosphere (anyone is an expert of his/her everyday life and habitat), and science continuously challenges the assessment with new and revived findings, against which a robust assessment demonstrating a basis on a credible system understanding is one of the few defences.

Thus, it is reasonable to expect a mature safety case to integrally include a comprehensive biosphere assessment. However, there have already been since the 1980s, some fear that a comprehensive, site-specific biosphere assessment would consume too many resources, that there would be no end to the necessary background research, and that this would pose a risk to meeting the milestones of the overall repository programme. It is also notoriously difficult to formulate meaningful scenarios for the biosphere over the very long time spans. In other words, a full-scale biosphere assessment can be perceived to introduce 'additional uncertainties' compared to the commonly used stylised reference biospheres that assume specific, usually unchanging, settings for the biosphere instead of attempting to depict the expected features, events and processes of the specific site. Taken to an extreme, such reference biospheres have consisted merely of a well used as a source of drinking water only (Vieno, 1994). On the other hand, the most recent biosphere assessment for the same spent nuclear fuel repository programme in Finland that earlier applied the drinking water well as the representation of the biosphere (e.g. Vieno and Nordman, 1999) considers now dynamic change in the landscape as a result of the post-glacial land uplift and includes hundreds of time-dependent biosphere objects, each of which comprises of several compartments and transfer equations (Posiva, 2013a). Reaching this level of comprehensiveness has required significant efforts in site characterization (e.g. Posiva, 2013b) and modelling. Similar levels of presentation of the biosphere have also been applied in the most recent Swedish assessments (e.g. Avila et al., 2013; Lindborg et al., 2013), supported by an extensive site characterization programme as well as data analysis.

These recent examples are in line with the expectations of the safety cases becoming more over-arching and comprehensive with the continuous improvement as the repository programmes get more mature, as it is clear that the behaviour and the impact of such repository cannot be considered in isolation from the surface environment. However, the comprehensiveness seems to be related to complexity of the models and to lead to difficulties in brief and clear presentation. There are merits both in the comprehensive and complex and in the stylised representations of the biosphere, as discussed in this paper by using the Finnish regulations and recent safety cases for nuclear waste disposal as examples. As the safety case methodology is rather generic, these considerations should be relevant to most nuclear waste repositories for other waste types as well.

\section{Biosphere assessment requirements and expectations}

\section{International regulations, guidance and examples}

In the fundamental safety principles of the International Atomic Energy Agency (IAEA, 2006), it is stated that "people and the environment, present and future, must be protected against radiation risks", that "radioactive waste must be managed in such a way as to avoid imposing an undue burden on future generations", and that "where effects could span generations, subsequent generations have to be adequately protected without any need for them to take significant protective actions". In practice, there is a clear need to evaluate the future risks within the present-day framework and risk perceptions. More technically, this implies the application of the present radiation protection framework and thus a need for a dose assessment that identifies and quantifies the relevant exposure pathways. Furthermore, as no protective actions by the future generations shall be assumed, the dose assessment needs to sufficiently cover a whole range of plausible scenarios in respect of the biosphere and people living in it.

For biosphere assessments, IAEA's BIOMASS programme (IAEA, 2003) presented guidance in establishing reference biospheres. The more recent EMRAS II and MODARIA programmes of the IAEA have had working groups to develop the approach further to take environmental changes into account. For the radiation protection, the recommendations of the International Commission on Radiological Protection (ICRP) have been widely accepted as the basis of the regulations. The BIOPROTA Forum (www.bioprota.org) has been active to foster information exchange between nuclear waste organizations. However, as present stages of deep geological repository programmes vary widely, such requirements for and expectations 
of biosphere assessments in the mature stages are not very clear. The same can be said on the results of working groups on safety case in more general (e.g. NEA, 2004, 2013; Galson and Richardson, 2011), although it is rather clear that reliability, credibility, traceability, transparency and clarity (e.g. STUK, 2014) are to be cherished as well as checking for comprehensiveness and synthesis of multiple lines of evidence (e.g. NEA, 2012).

\section{Finnish national requirements}

In the Finnish legislation, Government Decree 736/ 2008 states that for nuclear waste disposal a safety case is required and that it shall comprise a numerical analysis based on empirical research and of complimentary considerations. Furthermore, models and input data shall be based on highquality research and expert judgement, shall be validated when possible, shall be representative to the conditions likely prevailing at the site, and shall overestimate the release of radioactivity and the radiation doses with a high degree of confidence. Not only uncertainties but also their meaning shall be assessed. The degree sets the long-term safety criteria in terms of annual doses to the most exposed (below $0.1 \mathrm{mSv}$ ) and the other exposed persons (insignificantly small) for the period of the first several millennia and gives the nuclear safety authority the task to set constraints for radioactivity release rates from the nuclear waste to the biosphere so that the radiation impacts do not exceed those from natural radioactivity in the ground. In addition, potential impacts on plant and animal species shall be assessed.

The nuclear safety guides given by the Finnish Radiation and Nuclear Safety Authority, STUK, substantiate further the requirements in the legislation. Here, with most relevance STUK (2014) requires that the performance of the disposal system (including the 'natural environment', i.e. the biosphere) and the site conditions need to be described based on conceptual models that cover phenomena and processes controlling the release and transport of the radionuclides. These conceptual models are to be used to derive, usually through simplification, the actual assessment models. The safety case shall present analysis of scenarios that have been formulated systematically, and it shall be documented in a clear, transparent and traceable manner. The aleatory variability shall be included in the data and in the models. In addition to these general requirements for a safety case, the guide presents relatively few biosphere-specific requirements; here most importantly that the changes in the living environment that arise from changes in ground and sea level need to be taken into account (the Olkiluoto repository site is in the area of still continuing post-glacial crustal rebound). On the other hand, the guide allows for the assumption of non-changing climate type, human habits, nutritional needs and metabolism and biota populations. It is to be noted that the revised guide (STUK, 2014) applies to all geological disposal of nuclear waste from the generation of nuclear energy, that is, also the low- and intermediate-level waste that was earlier regulated separately (STUK, 2001, 2003).

\section{Societal expectations}

In addition to the general requirements for and expectations of safety cases, there are also wider cultural and economical expectations also within the nuclear community itself, predictability and continuity of the repository programmes not being the least. The scientific community, by its very nature, challenges the safety cases and expects scientific credibility. The general public seem to have most interest in the biosphere over all other parts of the safety case, regardless of the safety relevance, but this is not surprising as everyone is an expert of their living environment and concerned about it. Thus, it is usually difficult to convince the general public of the treatment of the biosphere being sufficient with less detail and comprehensiveness than the more technical parts of the disposal system even though that would be the case, at least within certain bounds. Overall, the whole range of societal expectations could be said to revolve around achieving and maintaining the overall reliability and credibility of the safety case and thus the acceptability of the whole disposal concept. This requires (Vira, 2014), in turn, use of best knowledge and practices, open discussion and debate in scientific and technical fora and constant re-assessing of issues where new information emerges; even though most of the safety case is understandable only to experts, it has to be open and readable to the wider community, too.

\section{Discussion}

From the discussion presented, it is clear that there is demand for demonstrating a high level of system understanding (i.e. comprehensive identification of features, events, processes and other factors that may have safety relevance or that may affect the 
doses) also in respect of the biosphere. This also involves systematic formulation of the biosphere scenarios and fitting models and data of high empirical quality consistently in this framework. This is to ensure that no factors that might increase the estimated radiation exposure are overlooked and that a fair view on the plausible range of radiation exposures can be obtained. Otherwise it would be difficult to derive reliable indicators taking the various accumulation processes and the various exposure groups sufficiently into account; demonstration of the comprehensiveness would be difficult without sufficient system understanding.

System understanding is important also for selection of appropriate assessment input data. It is generally considered that site-specific data are more representative of the repository and its biosphere than generic data (e.g. Caffrey et al., 2014) but, for example, in the case of the Olkiluoto site in Finland the post-glacial land uplift is expected to initiate formation of lakes and mires lacking from the site at the present and thus a reference site analogous to the expected conditions is used for the empirical study (Haapanen et al., 2011). Use of analogues is necessary at least in such cases in which applicable data are not directly available (IAEA, 2010) but also to improve conceptual modelling (IAEA, 1999). However, analogue data should be used with care and justified well (IAEA, 1999, 2010), especially since the radioecological parameters are influenced by many factors associated with the properties of the radionuclide, the organism and the ecosystem (e.g. Roivainen, 2011; Caffrey et al., 2014). The same applies also to replacing change in time with change in spatial location (e.g. Staudt et al., 2013; Becker et al., 2014) when justifying the models and data for environmental and climatic changes over very long time frames. In the reality of the assessment work, use of natural analogues and data on analogous nuclides, organisms and other entities is a necessity but without a credible justification, the validity of such inputs and thus also the overall results could be easily contested.

Instead of comprehensive and ambitious biosphere assessments, most engineers and some scientists might accept use of carefully derived stylised reference models or safety indicators. There are also benefits in stylised modelling. One of the most prominent benefits is the perceived avoidance of the complex nature and the inherent uncertainties of the biosphere. There is some persistent criticism that the complex and mechanistically rich models in ecology were 'data hungry', non-transparent, prone to error multiplication and difficult to test rigorously (DeAngelis and Mooij, 2003). Oreskes (2003) described this 'complexity paradox' as that "the more we strive for realism by incorporating as many as possible of the different processes and parameters that we believe to be operating in the system, the more difficult it is for us to know if our tests of the model are meaningful". In other words, it may never be possible to prove a certain model setting correct due to the complexities inherent in natural systems (Oreskes, 2003). As a comparison, simpler models are at least easier to replace by something better (Carpenter, 2003). It is also rather clear that simpler models are easier to communicate and be explained to the various audiences. However, the simpler the models, the higher the degree of pessimism needed to meet the criteria for a valid safety case, and this could cloud the thinking and the risk perception. Also, at least according to the Finnish regulations, even the simpler models need to be justified based on wellestablished system descriptions and on the meaning of the features, events, processes and other factors to the system behaviour and to the radiological impact. It may be also asked if there is an end to the simplification - a partial answer to this may be the example of reducing the biosphere into a mere drinking water well with a relatively low dilution of the releases (Vieno, 1994), which was perceived as a conservative dose indicator for rather a long time, that is, until it was shown that long-term accumulation in a peat bog might result in even higher doses (Bergström et al., 1999; Karlsson and Bergström, 2000), even though the bog model of the time lacked some accumulation processes, for example due to the growth of the peat layer. So, demonstrating the comprehensiveness may become an issue with the simpler models as well.

As already touched upon, the 'mechanistically rich' models (Canham et al., 2003; DeAngelis and Mooij, 2003) have the benefit of representing the complexity of the complex ecosystem being modelled (Oreskes, 2003) and such models are more powerful in the synthesis and integration of data, in guiding the empirical work, and in making testable model predictions (Canham et al., 2003). They also operate on the scales of the targets of the empirical study and thus can utilize larger amounts of field data (DeAngelis and Mooij, 2003). The complexity of these models is also balanced by allowing more realistic constraints to be set on the model and the parameters and by minimizing the impact of errors in any single variable and of error propagation (DeAngelis and Mooij, 2003; Oreskes, 
2003). Mechanistically rich models also relate their assumptions better to conceptual models derived from observations and to the behaviour of the ecosystem expected by ecologists, which can be seen to improve the transparency of the modelling (DeAngelis and Mooij, 2003). Thus, overall effort may be reduced by choosing an appropriate level of complexity as it may save from the justification of the simplification of the system in understanding the assessment models.

Clearly, there are benefits in both stylised and mechanistically rich modelling approaches that serve to fulfil the different requirements for and expectations of biosphere assessment. However, the issue of how to know that an adequate level of knowledge has been reached, by either simplification or elaboration (or rather, both), remains. To help in this, a Knowledge Quality Assessment procedure has been developed (Ikonen, 2006; Posiva, 2013a, 2014) in the biosphere part of the programme for the spent nuclear fuel repository at Olkiluoto, Finland. In the procedure, for example the main assumptions, the remaining main uncertainties and the strengths and weaknesses of the data basis are evaluated and their sources and effects identified systematically. It is recognized, though, that the required level of knowledge quality is dependent on the maturity of the repository programme and that the milestones of the overall programme set the pace. This quality is, of course, to be reflected against the regulatory and societal requirements and expectations of what is an acceptable level for the basis of the needed decisions.

\section{Conclusions}

As described above, a biosphere assessment is considered as an integral part of a whole-system safety case for a geological repository of nuclear waste. Correspondingly, there has also to be system understanding solid enough regarding the biosphere so that it can support comprehensive analysis of features, events and processes affecting the system behaviour, systematic formulation of assessment scenarios and selection and use of models and data appropriate to the assessment context. This understanding of the biosphere needs to demonstrate confidence in appropriate levels of pessimism but to retain a tie to recognizable realism. The biosphere assessment also needs to be able to model the system in sufficient detail to allow comparison with the present-day level of radiation protection and radiation risks. To achieve all this, significant effort is expected from mature repository programmes.
Clearly, to assist in this, increased mutual transfer of knowledge with other applications of ecosystem sciences would be beneficial.

In respect of the practical implementation, both stylised and mechanistically rich models have their benefits as discussed in this paper. The necessity of justifying the simplifications of the system understanding into the models and input data might favour more complex models, but on the other hand the simpler models seem easier to communicate at least outside the scientific disciplines in question, as long as they are not too simple to make sense.

In practice, however, the story is often more important than the ending - it is not considered sufficient just to show compliance with the radiological constraints if the assessment process cannot withstand the demand of credibility and reliability towards, and confidence and trust from, the various audiences. To achieve this, more work might be required than would be the mere technical necessity; the biosphere in the assessments also needs to resemble the living environment, even though this would result in challenges in management of the inherent uncertainties in nature.

\section{Acknowledgements}

The views presented in the paper are those of the author, and do not necessarily coincide with those of the related organizations. The work has been funded by EnviroCase Ltd., although it is largely based on ideas and experience gained by the author while working earlier for Posiva $\mathrm{Oy}$, the company responsible of the spent nuclear fuel repository programme at Olkiluoto, Finland, and in numerous international working groups over the years.

\section{References}

Avila, R., Kautsky, U., Ekström, P.-A., Åstrand, P.-G. and Saetre, P. (2013) Model of the long-term transport and accumulation of radionuclides in future landscapes. AMBIO, 42, 497-505.

Becker, J.K., Lindborg, T. and Thorne, M.C. (2014) Influence of climate on landscape characteristics in safety assessments of repositories for radioactive wastes. Journal of Environmental Radioactivity, 138, 192-204.

Bergström, U., Nordlinder, S. and Aggeryd, I. (1999) Models for Dose Assessments: Modules for Various Biosphere Types. Technical Report TR-99-14. Swedish Nuclear Fuel and Waste Management Co., Stockholm. Caffrey, E.A., Leonard, M.E., Napier, J.B., Neville, D.R. and Higley, K.A. (2014) Radioecology: Why bother? Journal of Environmental Protection, 5, 181-192. 
Canham, C.D., Cole, J.J. and Lauenroth, W.K. (2003) Models in ecosystem science. Pp. 1-10 in: Models in Ecosystem Science (C.D. Canham, J.J. Cole and W.K. Lauenroth, editors). Princeton University Press.

Carpenter, S.R. (2003) The need for fast-and-frugal models. Pp. 455-460 in: Models in Ecosystem Science (C.D. Canham, J.J. Cole and W.K. Lauenroth, editors). Princeton University Press.

DeAngelis, D.L. and Mooij, W.M. (2003) In praise of mechanistically rich models. Pp. 63-82 in: Models in Ecosystem Science (C.D. Canham, J.J. Cole and W.K. Lauenroth, editors). Princeton University Press.

Galson, D.A. and Richardson, P.J. (2011) PAMINA, Performance Assessment Methodologies in Application to Guide the Development of the Safety Case (Contract Number: FP6-036404): Project Summary Report. European Commission.

Haapanen, R., Aro, L., Koivunen, S., Lahdenperä, A.-M., Kirkkala, T., Hakala, A., Helin, J. and Ikonen, A.T.K. (2011) Selection of real-life analogues for future lakes and mires at a repository site. Radioprotection, 46, S647-S651.

IAEA (1999) Use of natural analogues to support radionuclide transport models for deep geological repositories for long lived radioactive wastes. IAEATECDOC-1109. International Atomic Energy Agency (IAEA), Vienna.

IAEA (2003) "Reference Biospheres" for solid radioactive disposal: Report of BIOMASS Theme 1 of the BIOsphere Modelling and ASSessment (BIOMASS) Programme, Part of the IAEA Co-ordinated Research Project on Biosphere Modelling and Assessment (BIOMASS). IAEA-BIOMASS-6. International Atomic Energy Agency (IAEA), Vienna.

IAEA (2006) Fundamental Safety Principles. IAEA Safety Standards Series No. SF-1. International Atomic Energy Agency (IAEA), Vienna.

IAEA (2010) Handbook of parameter values for the prediction of radionuclide transfer in terrestrial and freshwater environments. Technical Report Series 472. International Atomic Energy Agency (IAEA), Vienna.

Ikonen, A.T.K. (2006) Posiva Biosphere Assessment: Revised Structure and Status 2006. POSIVA 2006-07. Posiva Oy, Olkiluoto, Finland.

Karlsson, S. and Bergström, U. (2000) Dose rate estimates for the Olkiluoto site using the biosphere models of SR 97. Working Report 2000-20. Posiva Oy, Helsinki.

Lindborg, T., Brydsten, L., Sohlenius, G., Strömgren, M., Andersson, E. and Löfgren, A. (2013) Landscape development during a glacial cycle: Modeling ecosystems from the past into the future. AMBIO, 42, 402-413.

NEA (2004) Post-closure Safety Case for Geological Repositories: Nature and Purpose. NEA No. 3679. Nuclear Energy Agency (NEA), Organisation for Economic Co-operation and Development (OECD).
NEA (2012) Methods for Safety Assessment of Geological Disposal Facilities for Radioactive Waste: Outcomes of the NEA MeSA Initiative. NEA No. 6923. Nuclear Energy Agency (NEA), Organisation for Economic Co-operation and Development (OECD).

NEA (2013) The Nature and Purpose of the Post-closure Safety Cases for Geological Repositories: "Safety Case Brochure 2012”. NEA/RWM/R(2013)1. Nuclear Energy Agency (NEA), Organisation for Economic Co-operation and Development (OECD).

Oreskes, N. (2003) The role of quantitative models in science. Pp. 13-31 in: Models in Ecosystem Science (C.D. Canham, J.J. Cole and W.K. Lauenroth, editors). Princeton University Press.

Posiva (2013a) Safety Case for the Disposal of Spent Nuclear Fuel at Olkiluoto - Biosphere Assessment 2012. POSIVA 2012-10. Posiva Oy, Eurajoki, Finland.

Posiva (2013b) Olkiluoto Biosphere Description 2012. POSIVA 2012-06. Posiva Oy, Eurajoki, Finland.

Posiva (2014) Knowledge quality assessment methodology. pp. 45-50 in: Safety Case for the Disposal of Spent Nuclear Fuel at Olkiluoto - Data Basis for the Biosphere Assessment BSA-2012, Part I. POSIVA 2012-28. Posiva Oy, Eurajoki, Finland.

Roivainen, P. (2011) Characteristics of Soil-to-Plant Transfer of Elements Relevant to Radioactive Waste in Boreal Forest. Dissertations in Forestry and Natural Sciences, 56. University of Eastern Finland.

Staudt, C., Semiochina, N., Kaiser, J.C. and Pröhl, G. (2013) Modeling the impact of climate change in Germany with biosphere models for long-term safety assessment of nuclear waste repositories. Journal of Environmental Radioactivity, 115, 214-223.

STUK (2001) Long-term Safety of Disposal of Spent Nuclear Fuel. Guide YVL 8.4. Radiation and Nuclear Safety Authority (STUK), Helsinki.

STUK (2003) Disposal of low and intermediate level waste from the operation of nuclear power plants. Guide YVL 8.1. Second, revised edition. Radiation and Nuclear Safety Authority (STUK), Helsinki.

STUK (2014) Disposal of Nuclear Waste. Guide YVL D.5. Radiation and Nuclear Safety Authority (STUK), Helsinki.

Vieno, T. (1994) WELL-94: A Stylized Well Scenario for Indicative Dose Assessment of Deep Repositories. Report YJT 94-19. Nuclear Waste Commission of Finnish Power Companies, Helsinki.

Vieno, T. and Nordman, H. (1999) Safety Assessment of Spent Fuel Disposal in Hästholmen, Kivetty, Olkiluoto and Romuvaara, TILA-99. Report POSIVA 99-07. Posiva Oy, Helsinki.

Vira, J. (2014) Vain turvallinen loppusijoitus on mahdollinen (in Finnish; Only safe disposal is possible). Pp. 14-16 in: Ytimekäs 1/2014 (J. Aho, editor). Teollisuuden Voima Oyj, Olkiluoto, Eurajoki, Finland. 